http://jmscr.igmpublication.org/home/ ISSN (e)-2347-176x ISSN (p) 2455-0450

crossref DOI: https://dx.doi.org/10.18535/jmscr/v8i8.36

\title{
Is There a Difference in the Resistance to Erythropoietin Stimulating Agents in Dialysis Patients Depending on Whether or not they Received such Treatment Before Starting Hemodialysis?
}

\author{
Author \\ Krasimira Atanasova Ashikova \\ Department of Dialysis Treatment, Sveta Anna Hospital AD Sofia Bulgaria \\ Address: Sofia 1 Dimitar Mollov str.
}

\begin{abstract}
Background: The aim of the present study was to investigate a differences in the resistance to Erythropoietin Stimulating Agents (ESAs) in dialysis patients, depending on Whether or not they received such treatment before starting hemodialysis.

Material and Methods: This was a cross-sectional study from January 2009 to January 2020, 775 patients with end-stage kidney disease, on hemodialysis treatment (HDT). For a 12 years, the following categories were monitored by sex: age, hemoglobin levels, ESA dosage, Erythropoietin resistance index (ERI) in patients on periodic dialysis treatment in the Department of Dialysis Treatment /DDT/, UMHAT Sveta Anna Sofia. The following methods were used: Questionnaire; Hemoglobin test; ERI calculation by formula; Statistical methods-methods of prospective follow-up, Data analysis-t-Test: Two-Sample Assuming Unequal Variances, Descriptive and deductive statistics, Parametric analysis.

Results: 1.A very large number of patients have initiated hemodialysis treatment in emergency, without knowing about their disease and were not monitored by a nephrologist and were not treated with ESAs before dialysis. 2.There is a statistically significant difference in the mean hemoglobin level in women who were ESA treatment-naüve before HD compared to men who were ESA treatment-nä̈ve before HD $(p=0.047006), 3$. There is a difference in terms of resistance-Erythropoietin Resistance Index(ERI) in were ESA treatment-nä̈ve before HD compared to men who were ESA treatment-nä̈ve before HD $(p=0.013)$.

Conclusion: It is necessary to expand the scope, follow-up and treatment in patients with nephrological diseases without waiting for the progression of the disease. When administering ESA, always take into account the sex of the patients and consider the specific characteristics of female patients.

Keywords: Hemoglobin, CKD, hemodialysis, anemia, Erythropoiesis-stimulating agents (ESAs), Erythropoietin resistance index (ERI).
\end{abstract}

\section{Background}

Anemia is frequently experienced by patients with non-dialysis-dependent chronic kidney disease (NDDCKD) ${ }^{1}$. The prevalence varies with the definition of anemia, but increases to $50 \%$ in CKD stage $4 / 5$. For many patients, anemia causes unpleasant symptoms, such as fatigue and shortness of breath. In recent years, the recognition of serious adverse risks associated with erythropoietin analogue treatment may have drawn attention away from the importance of anemia-related symptoms. Depending on severity 
and duration, these symptoms can significantly degrade the richness and quality of a patient's life. In addition, anemia in NDD-CKD causes an increased likelihood for blood transfusions and is associated with (but may not be a cause of) a higher prevalence of left ventricular hypertrophy and greater risk for hospitalizations and death $^{2^{-}} 4$.

TREAT, CREATE, and CHOIR were studies of erythropoietin analogues. There are multiple published studies that have indicated concern about treatment with erythropoietin analogues to the high doses required to reach high hemoglobin levels $5^{-7}$. The use of the high doses associates more closely with adverse outcomes in the large anemia Randomized controlled trials(RCTs) than achieved hemoglobin levels ${ }^{7}, 8$ It is clear from TREAT, CHOIR, and CREATE that high-dose erythropoietin analogues should not be used to increase the hemoglobin level to normal hemoglobin targets $(>13 \mathrm{~g} / \mathrm{dL})$.

How high should the hemoglobin level be increased? Unfortunately, CREATE, CHOIR, and TREAT leave unanswered whether the hemoglobin range of risk extends to hemoglobin targets $<13 \mathrm{~g} / \mathrm{dl}$. Without such knowledge, and in the absence of RCTs of intermediate hemoglobin targets $(11,11.5$, and $12 \mathrm{~g} / \mathrm{dl})$, treatment of anemia inNDD-CKD must remain conservative. It would seem reasonable to avoid hemoglobin targets $>11 \mathrm{~g} / \mathrm{dl}$ in NDD-CKD to stay well clear of some of the risks uncovered by CREATE, CHOIR, and TREAT ${ }^{7}, 8$.

The debate in search of optimal target hemoglobin level, achieved by treatment with an erythropoiesis-stimulating agent (ESA) has been going on for many years. This is a review a the history of ESA use in patients with CKD, discussing changing guidance, benefits, limitations and appropriate use of ESAs in these patients. See Table 1 for a chronological listing of the key guidelines consulted.

In Bulgaria there is a well developed system for the treatment of anemia in patients with CKD stage 3-5 and are constantly updated ${ }^{9}$. The criteria for the inclusion of certain groups of medicines are precisely defined. Costly drugs $100 \%$ are reimbursed by the health fund. At the same time, there are many uncertainties about patients' resistance to anti-anemic treatment.

Despite changes in guidance, the question of whether focus should be directed on avoiding high $\mathrm{Hb}$ levels or avoiding high ESA doses in ESAresistant patients remained. A meta-regression analysis published in 2013 examined the association of ESA dose with adverse outcomes in $\mathrm{CKD}$, independent of the target or $\mathrm{Hb}$ level achieved $^{10}$. In 12,956 patients, all-cause mortality was associated with higher total-study-period mean ESA dose and higher first-3-month mean ESA dose. Total-study-period mean ESA dose and first-3-month ESA dose remained significant after adjusting for target $\mathrm{Hb}$ or first-3-month mean $\mathrm{Hb}$, respectively. Hypertension, stroke, and thrombotic events, including dialysis vascular access-related thrombotic events, were increased with higher total-study-period mean ESA dose ${ }^{10}$.

Erythropoiesis-stimulating agents have transformed the management of anemia in patients with CKD. Some studies suggesting they improve quality of life (QoL) in certain subsets of patients with anemia ${ }^{11^{-}} \mathbf{1 5}^{5}$. Although target $\mathrm{Hb}$ levels have been a key component of guidance, evolving data suggest that ESA dose and the speed at which $\mathrm{Hb}$ levels change in response to ESAs are also important considerations when treating anemic patients $^{16}$. Indeed, the latest product labeling no longer specifies a target $\mathrm{Hb}$ level, but use of the lowest ESA dose sufficient to reduce the need for transfusions. Biosimilar ESA products have been used successfully for many years, with safety and efficacy comparable to originator products, bringing cost savings to patients and healthcare systems, and increased access to ESAs and other expensive drugs due to reallocation of resources. Further research will provide guidance on individualization of ESA therapy for different patients and indications so that the optimal benefit to risk ratio may be achieved ${ }^{17}$. 
Resistance to ESA is common in patients undergoing chronic hemodialysis (HD) treatment. In many HD patients, target hemoglobin levels are not reached due to a varying degree of ESA resistance. A diminished response to ESA has been associated with various factors, including (functional) iron deficiency andvitamin deficiency, an impaired nutritional state and the presence of (micro) inflammation ${ }^{18}{ }^{\prime 19}$.

Furthermore, the microbiological purity of the dialysis fluid ${ }^{2 \circ}$, the presence of hyperparathyroidism ${ }^{21}$ and low dialysis adequacy $^{22}$ have been associated with ESA resistance.

There are no publications in the medical literature comparing ESA resistance in dialysis patients depending on whether or not they received ESA before initiating hemodialysis treatment. Unclear whether patients treated with ESAs before hemodialysis, after initiating renal replacement therapy have different hemoglobin levels and/or different resistance than ESA-naïve patients prior to dialysis. The number of dialysis patients in Bulgaria is constantly growing and currently exceeds 3700 people (3 763 in 2017). However, the number of CKD patients observed by a nephrologist who start periodic hemodialysis treatment as planned, as well as those who received ESA during the pre-dialysis period, remains small. The need for detailed studies related to the follow-up of this patient population is at the heart of this paper.

\section{Objective}

The aim of the present study was to investigate a differences in the resistance to Erythropoietin Stimulating Agents (ESAs) in dialysis patients, depending on whether or not they received such treatment before starting hemodialysis.

\section{Material and Methods}

Over a period of 12 years, the following categories were monitored by sex: age, hemoglobin levels, Erythropoietin Resistance Index ERI, ESA dosage in patients on periodic dialysis treatment in the Department of Dialysis Treatment /DDT/, UMHAT Sveta Anna AD Sofia, between 2009 and 2020. Patients were grouped into two groups: group A - patients who received ESA before the start of dialysis treatment, and group B - ESA treatment-naïve before starting dialysis treatment. 286 female and 489 male patients were followed. A total of 775 patients. A comparative analysis was performed between group A and group B by sex. The female patients in group A were compared to male patients in group $\mathrm{A}$, and female patients in group $\mathrm{B}$ were compared to male patients in group $\mathrm{B}$. The following categories were compared: age, mean hemoglobin level, ESA mean weekly dose, ESA mean weekly dose/kg body weight, and Erythropoietin Resistance Index (ERI).

Methods: 1. Questionnaire. All study subjects were interviewed using a standardized questionnaire to provide the following data: gender, age, weight, monitoring during the predialysis period, ESA administration during the pre-dialysis period. 2. Method of hemoglobin testing (Colorimetric method at the University Hospital Sveta. Anna Sofia laboratory) 3. Erythropoietin Resistance Index (ERI) calculation by formula: ESA weekly dose/ body weight in $\mathrm{kg} / \mathrm{hemoglobin}$ in $\mathrm{g} / \mathrm{dl}$. 4. Statistical methods. The methods of prospective follow-up were used, Data analysis - t-Test: Two-Sample Assuming Unequal Variances, Descriptive and deductive statistics, Parametric analysis, Descriptive statistics: point estimates of parameters-finding averages.

\section{Results and Discussion}

Table 2, Chart 1 and Chart 2 show data of patients who were monitored by a nephrologist before initiating $\mathrm{HD}$; ESA treatment before HD. Annually, at the beginning of January, patients were interviewed through a standardized questionnaire to provide the following data: gender, age, monitoring during the pre-dialysis period, ESA administration during the pre-dialysis period. Patients are examined for complete blood 
counts and chemistry, the weekly dose per patient is monitored, as well as the weekly dose per $\mathrm{kg} /$ weight, and ERI is calculated for each patient. Table 2 presents the data from the follow-up of patients in the years 2009-2020. It is important to note that the patients on periodic hemodialysis treatment who had started such treatment in emergency and patients with previously unknown CKD form much larger proportion.

It is obvious at first glance that there is a large number of patients who initiated emergency treatment. In all those 12 years, the percentage of monitored patients before the initiation of periodic hemodialysis treatment was not higher than $53.62 \%$. The highest number of patients was observed in $2014-53.62 \%$, and the lowest number of patients was observed in $2018-25.4 \%$. The statistics are similar for patients who received ESA during the pre-dialysis period. The highest is the number of monitored patients who received ESA in $2010-34.78 \%$, and the lowest in 2018 $15.78 \%$. The data for the USA for the period 1995-2012 were similar ${ }^{23}$. While in the USA this rate was around $15 \%$ by 2012 , the rate at DDT, Sveta Anna Hospital Sofia was between $15.78 \%$ and $34.48 \%$ for the period $2009-2020$.

Comparing the data from the results, it was found that there is no statistically significant difference in the mean hemoglobin levels of the two groups of female patients (group A compared to group B, i.e. patients who received ESA or were ESA treatment-naïve before the start of HD) $(\mathrm{p}=0.1373)$. No such difference was found in men $(p=0.246)$ - Table 3. The results for the period 1995-2012 are similar for patients from the USA in terms of hemoglobin levels and comparison of the two groups of patients, i.e. with and without ESA treatment. There is no gender grouping in their follow-up ${ }^{24}$. However, in our patients, there was a statistically significant difference in the mean hemoglobin level of female patients who were ESA treatment-naïve (group B) before HD compared to male patients (group B) who were ESA treatment-naïve $(p=0.047006)$. Female patients showed significantly lower hemoglobin level $(9.345 \pm 0.25 \mathrm{~g} / \mathrm{l})$. In male patients, the mean value was $9.95 \pm 0.13 \mathrm{~g} / \mathrm{l}$. When comparing the mean hemoglobin levels in men and women receiving ESA (group A) there is no significant difference $(\mathrm{p}=0.833)$.

There is no data in the world literature to compare the results of the two groups of patients (with ESA treatment; ESA treatment-naïve before HD) in relation to ESA mean weekly dose, ESA mean weekly dose per $\mathrm{kg} /$ body weight, or ERI.

Table 4 shows the results of ERI calculation in both sexes and in both groups of patients. ERI calculation by formula: ESA weekly dose/ body weight in $\mathrm{kg} / \mathrm{hemoglobin}$ in $\mathrm{g} / \mathrm{dl}$. No statistically significant difference was found in the data for the different groups of patients (with ESA treatment/ ESA treatment-naïve). $\mathrm{P}=0.573$ for female patients. $\mathrm{P}=0.107$ for male patients. There is no difference in ERI mean value between men and women who received ESA before HD ( $p=0.473)$. There was a statistically significant difference in terms of resistance (ERI) female patients who were ESA treatment-naïve (group B) before HD compared to men (group B) who were ESA treatment-naïve before HD $(p=0.0098)$. Female patients show significantly higher resistance: mean ERI value $15.83 \pm 1.1862$. In male patients, mean ERI value is $12.00369 \pm 0.55$.

The Result of the long-term 12-year follow-up of the patients in the Department of Dialysis Treatment, Sveta Anna Hospital AD Sofia shows:

1. A very large number of patients have initiated periodic hemodialysis treatment in emergency, without knowing about their disease and were not monitored by a nephrologist.

2. There is a high percentage of patients on periodic hemodialysis treatment who were not treated with ESA before dialysis.

3. There is a statistically significant difference in the mean hemoglobin level in women who were ESA treatment-naïve (group B) before HD compared to men (group B) who were ESA treatment-naïve before HD $(p=0.047006)$. Female patients show a significantly lower hemoglobin level: 
$9.345 \pm 0.25 \mathrm{~g} / \mathrm{l}$. In male patients, the mean hemoglobin value is $9.95 \pm 0.13 \mathrm{~g} / \mathrm{l}$.

4. There is a statistically significant difference in terms of resistance (ERI) in were ESA treatment-naïve (group B) before HD compared to men (group B) who were ESA treatment-naïve before HD ( $\mathrm{p}=0.013)$. Female patients show significantly higher resistance: mean ERI value $15.83 \pm 1.1862$. In male patients, the mean value is $12.00369 \pm 0.55$.
5. There is no difference in the age of the two groups of patients compared by sex and between the sexes, nor in ESA mean weekly dose.

6. There is no statistically significant difference between the sexes when comparing ERI levels in group A (those who received ESA treatment before HD), $\mathrm{p}=0.473$.

Table 1 Guidelines and recommendations reviewed (1997-2018).

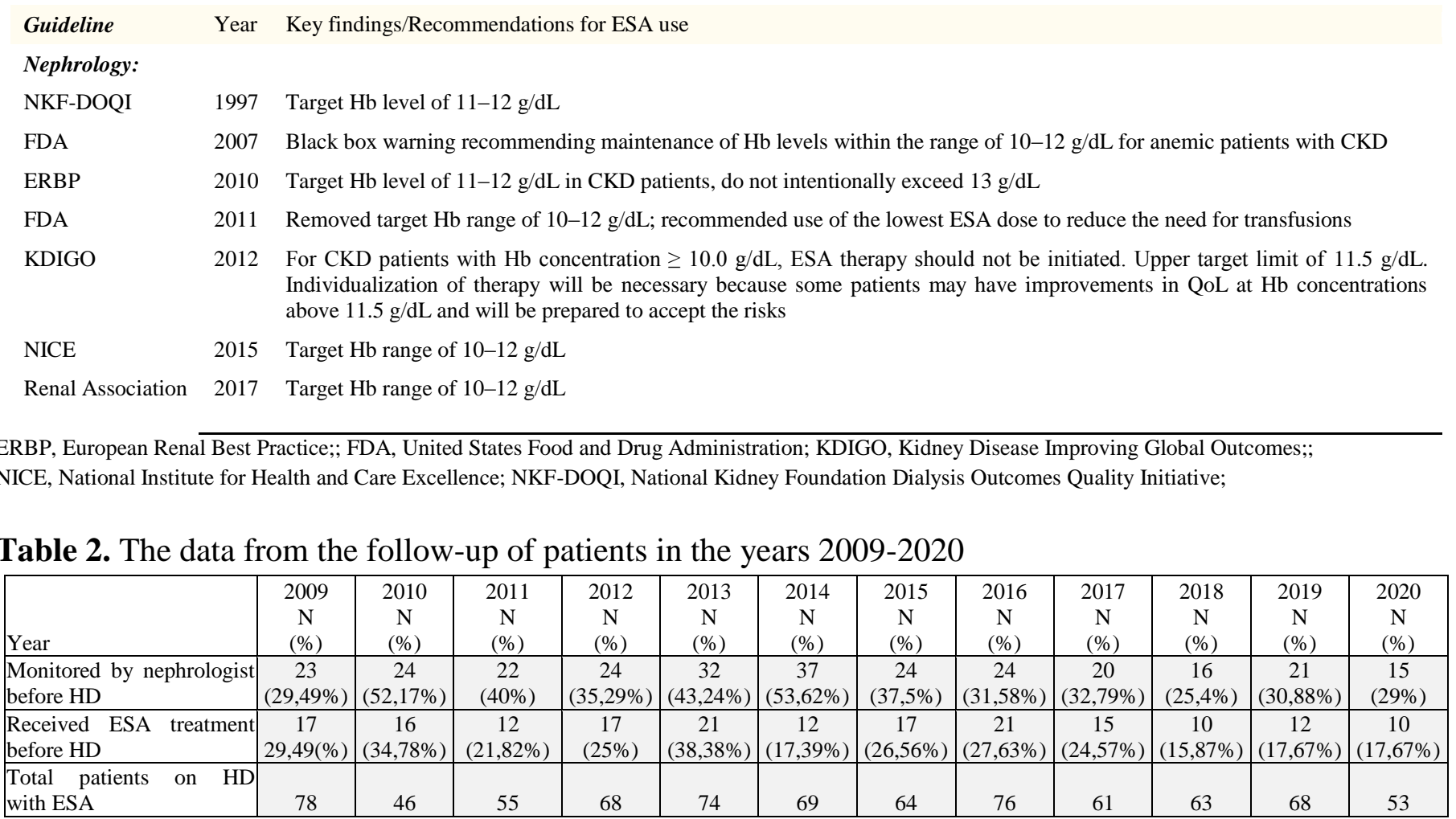

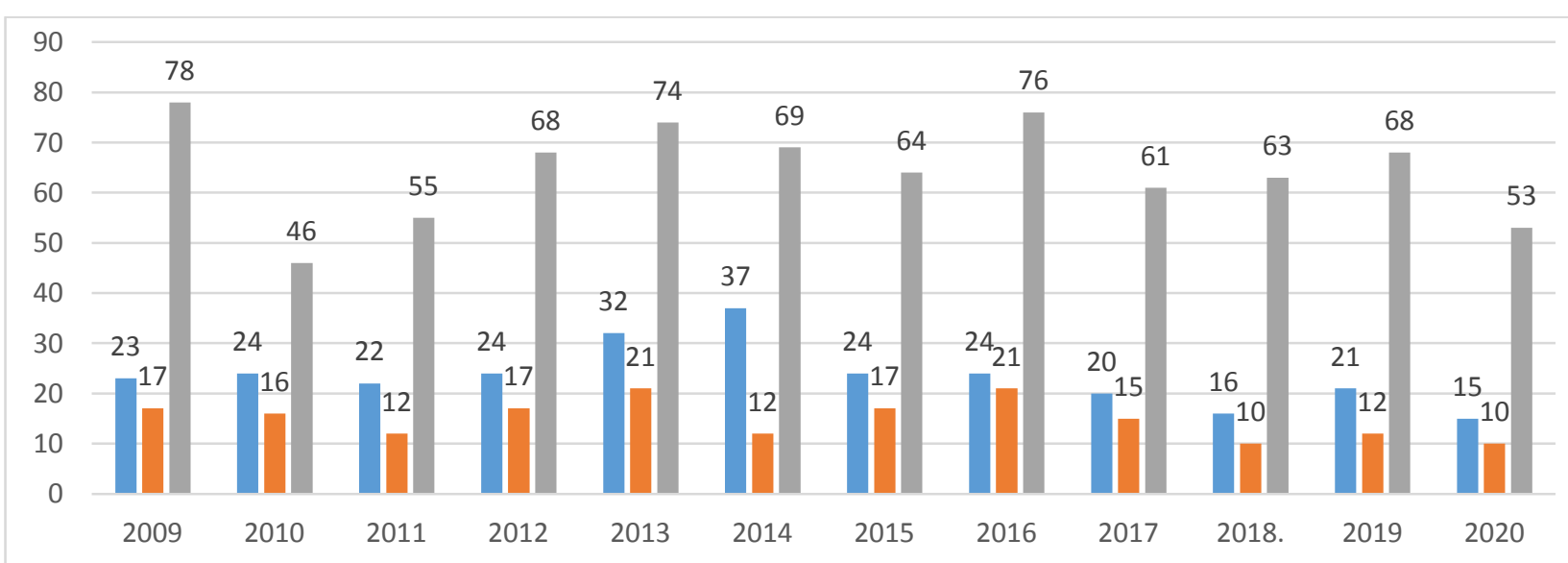

— Monitored by nephrologist before HD $\quad$ Received ESA treatment before HD $\quad$ Total patients on HD with ESA

Chart 1 The data from the follow-up of patients in the years 2009-2020 


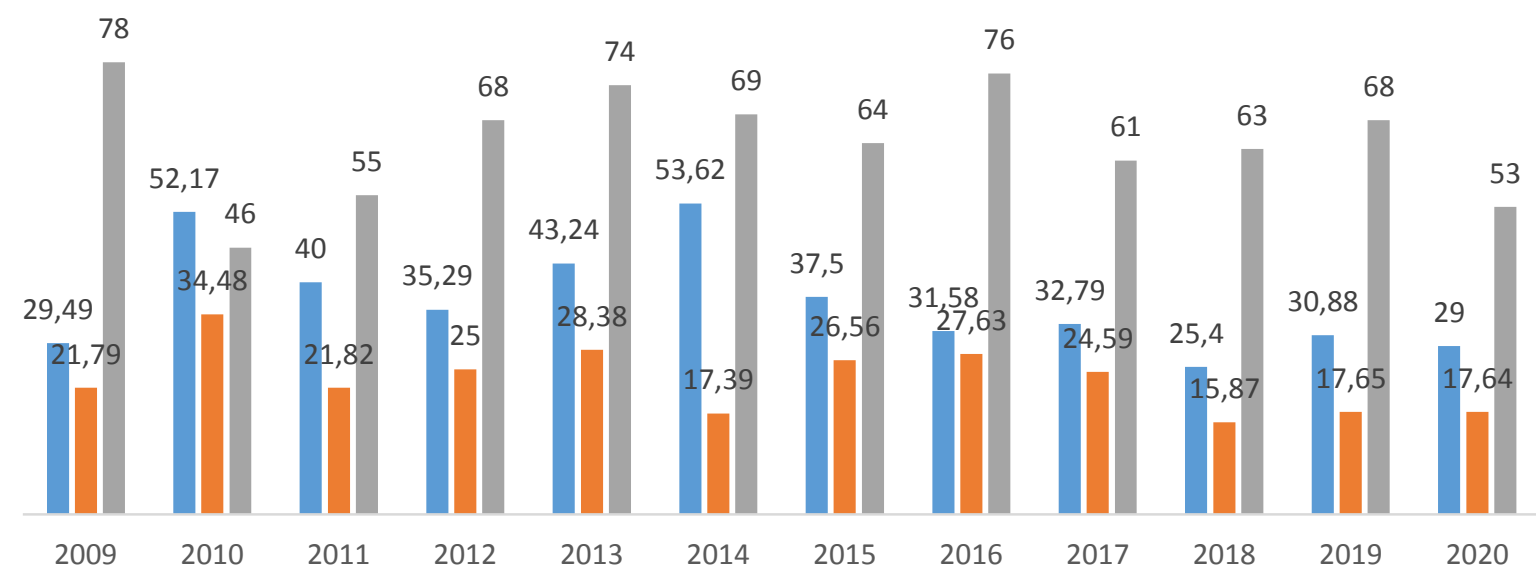

Monitored by nephrologist before HD $\quad$ Received ESA treatment before HD $\quad$ Total patients on HD with ESA

Chart 2 The data from the follow-up of patients in the years 2009-2020 in relative percentage

Table 3. Mean hemoglobin levels in male and female patients in both groups

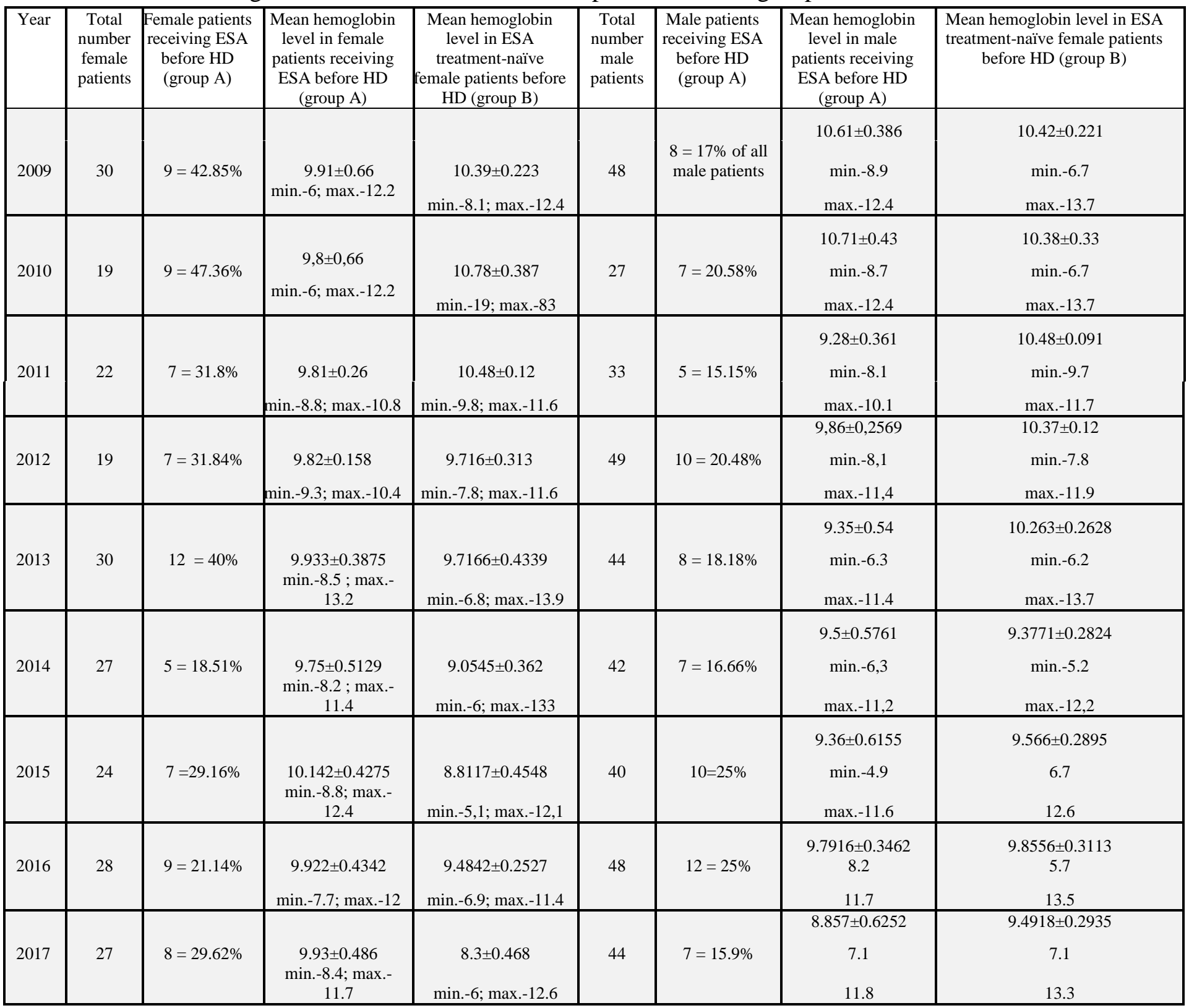




\section{JMSCR Vol||08||Issue||08||Page 197-206||August}

\begin{tabular}{|c|c|c|c|c|c|c|c|c|}
\hline 2018 & 22 & $96=27.27 \%$ & $\begin{array}{c}8.62 \pm 1.50 \\
\min .-7.6 ; \max .- \\
11.2 \\
\end{array}$ & $\begin{array}{c}8.33 \pm 0.540 \\
\text { min. }-4.4 ; \text { max. }-10.9\end{array}$ & 41 & $4=8.8 \%$ & $\begin{array}{c}10.55 \pm 0.3095 \\
9.7 \\
11.1 \\
\end{array}$ & $\begin{array}{c}9.587805 \pm 0.2751 \\
5.7 \\
13.3 \\
\end{array}$ \\
\hline 2019 & 19 & $97=36.84 \%$ & $\begin{array}{c}9.78 \pm 0.456 \\
\text { min.-8.4; } \max .- \\
11.3\end{array}$ & $\begin{array}{c}8.55 \pm 0.44 \\
\text { min.-5.2; max.- } 10.8\end{array}$ & 39 & $6=15.38 \%$ & $\begin{array}{c}9.3 \pm 0.6865 \\
6.8 \\
11.5 \\
\end{array}$ & $\begin{array}{c}10.3 \pm 0.28 \\
7.3 \\
14.4 \\
\end{array}$ \\
\hline \multirow[t]{4}{*}{2020} & 19 & $5(30 \%)$ & $\begin{array}{c}9.89 \pm 0.517 \\
\text { min.-8.4; } \max .- \\
11.3\end{array}$ & $\begin{array}{c}8.64 \pm 0.41 \\
\text { min.-4.9; max.-10.4 }\end{array}$ & 34 & $5(4.7 \%)$ & $\begin{array}{c}9.62 \pm 0.3813 \\
8.2 \\
10.3 \\
\end{array}$ & $\begin{array}{c}9.3482 \pm 0.3050 \\
6.7 \\
13.8 \\
\end{array}$ \\
\hline & & $\begin{array}{l}\text { Mean } \\
\text { Standard } \\
\text { Error }\end{array}$ & $\begin{array}{l}9.731666667 \\
0.172674301\end{array}$ & $\begin{array}{c}9.345 \\
0.251424728\end{array}$ & & & $\begin{array}{l}9.731666667 \\
0.172674301\end{array}$ & $\begin{array}{l}9.952608333 \\
0.131463361\end{array}$ \\
\hline & & Minimum & 8.85 & 8.3 & & & 8.85 & 9.34 \\
\hline & & Maximum & 10.71 & 10.78 & & & 10.71 & 10.48 \\
\hline
\end{tabular}

Table 4.The results of ERI calculation in both sexes and in both groups of patients

\begin{tabular}{|c|c|c|c|c|}
\hline Year & $\begin{array}{l}\text { ERI in female patients } \\
\text { receiving ESA before HD } \\
\text { (group A) }\end{array}$ & $\begin{array}{l}\text { ERI in female patients who were ESA } \\
\text { treatment-naïve before HD (group B) }\end{array}$ & $\begin{array}{l}\text { ERI in male patients receiving } \\
\text { ESA before HD (group A) }\end{array}$ & $\begin{array}{c}\text { ERI in female patients who } \\
\text { were ESA treatment-naïve } \\
\text { before HD (group B) }\end{array}$ \\
\hline 2009 & $\begin{array}{c}19.6 \pm 6.751 \\
\text { min.- } 0,42 ; \max .-55.05 \\
\end{array}$ & $\begin{array}{c}13.89 \pm 1.99 \\
\text { min.-2.64; } \max .-38.98 \\
\end{array}$ & $\begin{array}{c}12.67 \pm 3.10 \\
\min .-1.4 \\
\text { max.-27.36 } \\
\end{array}$ & $\begin{array}{c}\text { 9.7345 } \pm 1.130 \\
\min .-0 \\
\text { max.-33.58 } \\
\end{array}$ \\
\hline 2010 & $\begin{array}{c}19.80 \pm 6.64 \\
\text { min.-1.52; max.-55.059 } \\
\end{array}$ & $\begin{array}{c}8.718 \pm 0.985 \\
\text { min.-4.1; max.-14.6 }\end{array}$ & $\begin{array}{c}12.166 \pm 3.5436 \\
\min .-1.4 \\
\text { max.-27.36 }\end{array}$ & $\begin{array}{c}12.8995 \pm 2.43 \\
\min .-1.7 \\
\max .-41.8 \\
\end{array}$ \\
\hline 2011 & $\begin{array}{c}12.76 \pm 4.18 \\
\min .-0 \\
\max .-28.4\end{array}$ & $\begin{array}{c}9.1420 \pm 1.51 \\
\min .-2.608 \\
\max .-22.6142 \\
\end{array}$ & $\begin{array}{c}15.0745 \pm 5.644 \\
\min .-2.349 \\
\max .-35.4822\end{array}$ & $\begin{array}{c}10.7949 \pm 1.0437 \\
\min .-2.62123 \\
\max .-22.404\end{array}$ \\
\hline 2012 & $\begin{array}{c}11.10389 \pm 1.8102 \\
\text { min. }-4.5955 \\
\text { max.-18.61042 } \\
\end{array}$ & $\begin{array}{c}13.658 \pm 2.7470 \\
\text { min. }-0 \\
\text { max.-28.05 } \\
\end{array}$ & $\begin{array}{c}9.6384 \pm 2.0752 \\
\text { min. }-0 \\
\text { max.-23.894 }\end{array}$ & $\begin{array}{c}8.9887 \pm 0.7289 \\
\text { min. }-0 \\
\text { max. }-18.987 \\
\end{array}$ \\
\hline 2013 & $\begin{array}{c}13.99903 \pm 2.3650 \\
\text { min. }-0 \\
\text { max.- } 24,8139 \\
\end{array}$ & $\begin{array}{c}15.38976 \pm 2.1783 \\
\min .-0 \\
\text { max.-32.08556 }\end{array}$ & $\begin{array}{c}14.5867 \pm 2.7950 \\
\min .-0 \\
\text { max.-23894 } \\
\end{array}$ & $\begin{array}{c}9.917502 \pm 1.3143 \\
\min .-0 \\
\max .-35.27337 \\
\end{array}$ \\
\hline 2014 & $\begin{array}{c}12.784 \pm 3.516 \\
\text { min. }-0 \\
\text { max.-21.7037 }\end{array}$ & $\begin{array}{l}17.4817 \pm 1.7307 \\
\text { min. }-0 \\
\text { max.-33.05785 } \\
\end{array}$ & $\begin{array}{c}13.13563 \pm 2.5487 \\
\min .-2.1258 \\
\text { max.-22.9489 } \\
\end{array}$ & $\begin{array}{c}12.90811 \pm 1.32504 \\
0 \\
28.14259 \\
\end{array}$ \\
\hline 2015 & $\begin{array}{c}10.0658 \pm 2.1560 \\
\text { min. }-0 \\
\text { max.- } 17.04545\end{array}$ & $\begin{array}{c}17.50755 \pm 2.282566 \\
\text { min. }-0 \\
\text { max.-32.9912 }\end{array}$ & $\begin{array}{c}13.44 \pm 3.0231 \\
0 \\
30.2343 \\
\end{array}$ & $\begin{array}{c}11.1937 \pm 1.4334 \\
0 \\
30.12048 \\
\end{array}$ \\
\hline 2016 & $\begin{array}{c}11.44928 \pm 2.149045 \\
0 \\
1948052 \\
\end{array}$ & $\begin{array}{c}15.02234 \pm 1.6210 \\
2.7502 \\
26.5252 \\
\end{array}$ & $\begin{array}{c}9.8729 \pm 1.9644 \\
1.0175 \\
20.7039 \\
\end{array}$ & $\begin{array}{c}11.7762 \pm 1.4079 \\
0 \\
26.86968 \\
\end{array}$ \\
\hline 2017 & $\begin{array}{c}11.7434 \pm 2.9603 \\
0 \\
22,7272\end{array}$ & $\begin{array}{c}19.1943 \pm 2.6057 \\
0 \\
35.7142\end{array}$ & $\begin{array}{c}16.9653 \pm 2.9135 \\
5.2966 \\
29.97003\end{array}$ & $\begin{array}{c}12.9284 \pm 1.4629 \\
0 \\
30.2419\end{array}$ \\
\hline
\end{tabular}




\section{JMSCR Vol||08||Issue||08||Page 197-206||August}

\begin{tabular}{|c|c|c|c|c|}
\hline 2018 & $\begin{array}{c}11.78096 \pm 2.7276 \\
4,6904 \\
2160216\end{array}$ & $\begin{array}{c}22.54 \pm 3.505033 \\
4.80769 \\
56.81818\end{array}$ & $\begin{array}{c}10.97358 \pm 3.505033 \\
6.8027 \\
18.46438\end{array}$ & $\begin{array}{c}13.60247 \pm 1.134344 \\
6.8027 \\
18.46438\end{array}$ \\
\hline 2019 & $\begin{array}{c}23.66 \pm 2.3193 \\
13.0662 \\
30.30303 \\
\end{array}$ & $\begin{array}{c}19.79488 \pm 2.6887 \\
5.102 \\
37.0027 \\
\end{array}$ & $\begin{array}{c}18.80719 \pm 2.5281 \\
10.23018 \\
27.57353\end{array}$ & $\begin{array}{c}14.2744 \pm 1.3514 \\
0 \\
30.4414 \\
\end{array}$ \\
\hline 2020 & $\begin{array}{c}19.30099 \pm 5.1788 \\
6.41256 \\
30.30303 \\
\end{array}$ & $\begin{array}{c}17.70515 \pm 2.48445 \\
6.1274 \\
35.46099 \\
\end{array}$ & $\begin{array}{c}17.1362 \pm 5.6105 \\
6.5821 \\
38.8664 \\
\end{array}$ & $\begin{array}{c}15.0261 \pm 1.9095 \\
0 \\
45.3429 \\
\end{array}$ \\
\hline & $\begin{array}{c}\text { Mean-14.83 } \\
\text { Standard Error-1.294 } \\
\text { Minimum-10.06 } \\
\text { Maximum-23.66 }\end{array}$ & $\begin{array}{c}15.83625833 \\
1.186223189 \\
8.718 \\
22.54\end{array}$ & $\begin{array}{c}13.7039925 \\
0.8421756 \\
9.63 \\
18.8\end{array}$ & $\begin{array}{c}12.0036975 \\
0.551053466 \\
8.9887 \\
15.0261\end{array}$ \\
\hline
\end{tabular}

\section{Conclusion}

It is necessary to expand the scope, follow-up and treatment in patients with nephrological diseases without waiting for the progression of the chronic kidney disease. When administering ESA, always take into account the sex of the patients and consider the specific characteristics of female patients.

\section{References}

1. McClellan W, Aronoff SL, Bolton WK, et al. The prevalence of anemia in patients with chronic kidney disease. Curr Med Res Opin. 2004;20(9):1501-1510.

2. Sarnak MJ, Tighiouart H, Manjunath G, et al. Anemia as a risk factor for cardiovascular disease in the Atherosclerosis Risk in Communities (ARIC) study. J Am Coll Cardiol. 2002; 40(1):27-33.

3. Astor BC, Coresh J, Heiss G, Pettitt D, Sarnak MJ. Kidney function and anemia as risk factors for coronary heart disease and mortality: the Atherosclerosis Risk in Communities (ARIC) Study. Am Heart J. 2006;151(2):492-500.

4. Penninx BW, Pahor M, Woodman RC, Guralnik JM. Anemia in old age is associated with increased mortality and hospitalization. J Gerontol A BiolSci Med Sci. 2006;61(5):474-479. ${ }^{5}$ Nissenson AR,
Goodnough LT, Dubois RW. Anemia: not just an innocent bystander? Arch Intern Med. 2003;163(12): 1400-1404.

5. Fishbane S. Recombinant human erythropoietin: has treatment reached its full potential? Semin Dial. 2006;19(1):1-4.

6. Szczech LA, Barnhart HX, Inrig JK, et al. Secondary analysis of the CHOIR trial epoetin-alpha dose and achieved hemoglobin outcomes. Kidney Int. 2008;74(6):791-798.

7. Solomon SD, Uno H, Lewis EF, et al; Trial to Reduce Cardiovascular Events with Aranesp Therapy (TREAT) Investigators. Erythropoietic response and outcomes in kidney disease and type 2 diabetes. N Engl J Med. 2010;363 (12): 1146-1155.

8. Steven Fishbane, Daniel W. Ross, and Susana Hong Anemia in Non-DialysisDependent CKD: To Treat or Not to Treat? American Journal of Kidney DiseasesVolume 73, Issue 3, March 2019, Pages 297-299

9. Mila Liubomirova Anaemia in chronic kidney disease. Modern aspects of treatment. Sofia 2012

10. Koulouridis I, Alfayez M, Trikalinos TA, Balk EM, Jaber BL Dose of erythropoiesis-stimulating agents and adverse outcomes in CKD: a 
metaregression analysis. Am J Kidney Dis. 2013 Jan; 61(1):44-56.

11. Evans R. W., Rader B., Manninen D. L. (1990). The quality of life of hemodialysis recipients treated with recombinant human erythropoietin. Cooperative Multicenter EPO Clinical Trial Group. JAMA 1990 Feb $\quad 9 ; \quad 263825-830$. 10.1001/jama.1990.03440060071035 [PubMed] [CrossRef] [Google Scholar]

12. Parfrey P. S., Foley R. N., Wittreich B. H., Sullivan D. J., Zagari M. J., Frei D. (2005). Double-blind comparison of full and partial anemia correction in incident hemodialysis patients without symptomatic heart disease. J. Am. Soc. Nephrol. 2005;Jul; 16 2180-2189. 10.1681/ASN.2004121039 [PubMed] [CrossRef] [Google Scholar]

13. Drüeke TB, Locatelli F, Clyne N, Eckardt $\mathrm{KU}$, Macdougall IC, Tsakiris D, Burger HU, Scherhag A, CREATE Investigators. N Engl J Med. 2006 Nov 16; 355(20): 2071-84. [PubMed] [Ref list]

14. Singh AK, Szczech L, Tang KL, Barnhart H, Sapp S, Wolfson M, Reddan D, CHOIR Investigators Correction of anemia with epoetinalfa in chronic kidney disease.NEngl J Med. 2006 Nov 16; 355(20):2085-98. [PubMed] [Ref list]

15. Pfeffer MA, Burdmann EA, Chen CY, Cooper ME, de Zeeuw D, Eckardt KU, Feyzi JM, Ivanovich P, Kewalramani R, Levey AS, Lewis EF, McGill JB, McMurray JJ, Parfrey P, Parving $\mathrm{HH}$, Remuzzi G, Singh AK, Solomon SD, Toto $\mathrm{R}$, TREAT Investigators. A trial of darbepoetinalfa in type 2 diabetes and chronic kidney disease. N Engl J Med. 2009 Nov 19; 361(21):2019-32.[PubMed] [Ref list]

16. US Food and Drug Administration (2007a). FDA Advisory Committee Briefing Document. Joint Meeting of the Cardiovascular and Renal Drugs Advisory
Committee and the Drug Safety Risk Management Committee. Silver Spring, MD: U.S. Food and Drug Administration. [Google Scholar] [Ref list] 17. Matti Aapro, Pere Gascón, Kashyap Patel, George M. Rodgers, Selwyn Fung, Luiz H. Arantes, Jr.and Jay Wish Erythropoiesis-Stimulating Agents in the Management of Anemia in Chronic Kidney Disease or Cancer: A Historical Perspective Front Pharmacol. 2018; 9: 1498.Published online 2019 Jan 9. doi: 10.3389/fphar.2018.01498

PMCID: PMC6333861 PMID: 30687083

18. Singh AK, Szczech L, Tang KL, Barnhart H, Sapp S, et al. (2006) Correction of anemia with epoetinalfa in chronic kidney disease. N Engl J Med 355: 2085-2098.

19. Kalantar-Zadeh K, McAllister CJ, Lehn RS, Lee GH, Nissenson AR, et al. (2003) Effect of malnutrition-inflammation complex syndrome on EPO hyporesponsiveness in maintenance hemodialysis patients. Am J Kidney Dis 42: 761-773.

20. Locatelli F, Andrulli S, Memoli B, Maffei C, Del VL, et al. (2006) Nutritionalinflammation status and resistance to erythropoietin therapy in haemodialysis patients. 9.Susantitaphong $\mathrm{P}$, Riella C, Jaber BL (2013) Effect of ultrapure dialysate on markers of inflammation, oxidative stress, nutrition and anemia parameters: a meta-analysis. Nephrol Dial Transplant 28: 438-446.

21. Lee CT, Chou FF, Chang HW, Hsu YH, Lee WC, et al. (2003) Effects of parathyroidectomy on iron homeostasis and erythropoiesis in hemodialysis patients with severe hyperparathyroidism. Blood Purif 21: 369-375.

22. Movilli E, Cancarini GC, Zani R, Camerini C, Sandrini M, et al. (2001) Adequacy of dialysis reduces the doses of recombinant erythropoietin independently 
from the use of biocompatible membranes in haemodialysis patients. Nephrol Dial Transplant 16: 111-114.

23. US Renal Data System Annul Report, Volume 2,2014

24. Daniel W. Coyne, David Goldsmith, Ilian C. Macdougall New options for the anemia of chronic kidney disease Kidney Int Suppl (2011).2017Ｄec;7(3:157-163 Published online $2017 \quad$ Nov17. doi:10.1016/j.kisu.2017.09.002. 